\title{
DOES AGE AND GENDER MATTER IN STUDENTS' PERCEPTIONS OF INSTRUCTION EFFECTIVENESS IN ON-GROUND, ONLINE AND HYBRID COURSES?
}

\author{
Alan Peslak, Penn State University,arp14@psu.edu \\ Paul Kovacs, Robert Morris University, kovacs@rmu.edu \\ Gary Alan Davis, Robert Morris University, davis@rmu.edu \\ Wenli Wang, Robert Morris University,wangw@rmu.edu \\ Lisa Kovalchick, California University of Pennsylvania, kovalchick@calu.edu \\ Wendy Ceccucci, Quinnipiac University, wendy.ceccucci@quinnipiac.edu \\ John J. Scarpino, Pittsburgh Technical College, scarpino.john@ptcollege.edu
}

\begin{abstract}
This study examined the effect of age and gender of students on their perceived effectiveness of instructions in online, hybrid, and on-ground learning formats and their choice of online instruction. An online survey instrument was administered to students enrolled in Computer and Information Systems courses in two universities, and 376 students responded to the survey. First, it was found that age and gender has no impact with regard to the perceived effectiveness of on-ground education. Second, it was found that age, but not gender, has an effect on the perceived effectiveness of online education. Third, it was found that both age and gender have an impact with regard to hybrid education. Finally, neither age nor gender has an impact on the choice of online instruction method with the exception of an interaction effect.
\end{abstract}

Keywords: Online Education, Perceived Learning, Higher Education, Age, Gender

\section{INTRODUCTION}

Advances in communication technologies and the maturity of the Internet have enabled the development of alternatives to the traditional classroom teaching and learning process, and the way courses are delivered. These advances have resulted in technology-enabled learning, or online learning, and have enabled an increase of courses and programs in many disciplines that are available in the online format.

This study is an extension of a previous study conducted by the authors that examined different formats of learning. The current study probes deeper into various online learning formats, as well as the students who enroll in the courses. This study examines if age and gender of students affect perceived effectiveness of on-ground instruction, online instruction, and hybrid instruction. The study also examined if perception of prior effectiveness affects the students' choice of online instruction.

Many researchers have studied both age and gender with regard to technology use. As an example, there has been much gender study on text messaging. A number of research studies have found that females spend more time texting and send more messages in a day than do males (Balakrishnan \& Yeow, 2007; Fallows, 2005; Portio Research, 2012).. Igarashi, Jiro, and Toshikazu (2005) studied Japanese university freshman and looked at the gender differences in communication via text messaging. They determined that the volume of text messages did not vary by gender. However, the social relationship network maintained by text messaging was different. At later stages of text messaging, females tended to form a large group comparable to face-to-face communication. Pruthikrai (2007) found that gender had no significant effect on text-messaging activity.

Balakrishnan and Yeow (2007) looked at the physical aspects of texting, specifically the speed and efficiency of text entry. They found that females were more satisfied than males with texting, as a means of communication. They theorized two possible reasons for this satisfaction. First, females tend to have smaller fingers, making key pressing 
easier and faster. The second reason is that females' text more often, which makes them an expert in keying in the text. Vankatesh and Morris (2000) found that males and females differ in the adoption and use of technology in that women tend to be more open to the technology if it has a certain level of ease of use, and females tend to be more persuaded by peer-influenced normative pressures to adopt the technology than are males.

Peslak et al., (2013) found no difference in text messaging experience based on gender, with the exception of emotions. All of the positive emotions were higher for males than for females. In other words, males were more pleased, satisfied, contented, and delighted with their text messaging experience.

Herring and Zelenkauskaite (2009) looked at how text messaging is changing the way in which females and males have traditionally communicated. They analyzed over a thousand gender-defined messages posted on an Italian reality interactive music television channel. They found that females write longer messages, using more emoticons and abbreviations. Although females were both more economical and expressive, they came closer to "maxing out," or did "max out," on the 160-character message limit more often than their male counterparts. More recently, Kimbrough et al., (2013) found that females, compared to males, are generally more frequent communication users. Compared to men, women both prefer, and more frequently use, text messaging, social media and online video calls.

A number of researchers have studied both age and gender with regard to technology use. Venkatesh, Thong, and $\mathrm{Xu}(2012)$ used age and gender as moderating factors in their expanded study of the Unified Theory of Acceptance and Use of Technology (UTAUT), which is a technology acceptance model that aims to explain the degree of acceptance of the use of information technology and subsequent usage behavior. The model consists of four main constructs Performance Expectancy (PE), Effort Expectancy (EE), Social Influence (SI), and Facilitating Conditions (FC. These four constructs are independent variables which influence the dependent variables of usage and behavior. Age, gender, and experience of system use have indirectly influenced the dependent variables via the four main concepts. The authors concluded that age, gender and experience moderate the impact of hedonic motivation on behavioral intention and age and gender moderate the effect of price value on behavioral intention. Snell and SnellSiddle (2013) found no gender difference in the use of mobile technology tools but younger age group has a more positive attitude toward the use of technology.

Finally, several studies have examined the impact of societal norms on the use and acceptance of technology for learning. Moghaddam (2010) found a gender gap exists in technology use and such a gender gap is wider in more developed countries. To explain the gap, the author cited Hofstede's model that developed countries have a high Power Distance, which describes how people belonging to a specific culture view power relationships such as superior/subordinate relationships. In other words, people in cultures having a high power distance are very respectful to authority figures and normally accept an unequal division of power, while those in cultures having a low power distance willingly question authority and look forward to participating in decisions that affect them. As a result, more developed countries allow men to have greater access to technology for work and learning and hence higher levels of acceptance and use. Yau and Cheng (2012) confirmed the findings of previous studies that male students have more confidence in using technology for learning. The authors attribute the increased confidence to a societal view that computers and technology are a male-dominated activity. The authors found little difference between genders in terms of ability to use technology, however.

This research investigates if age and gender have effects on the students' perceived effectiveness of instructions in on-ground, online and hybrid courses. Specifically, the study intends to answer the following research questions:

1) Does age and/or gender of students affect perceived effectiveness of on-ground instruction?

2) Does age and/or gender of students affect perceived effectiveness of online instruction?

3) Does age and/or gender of students affect perceived effectiveness of hybrid instruction?

4) Does age and/or gender affect choice of instruction method?

\section{RESEARCH METHODOLOGY}

This study involved an online survey instrument that consisted of 23 closed-ended questions and was administered to students enrolled in CIS courses at two universities; one private and one public. Both schools were medium-sized 
institutions. The students at the private university consisted of undergraduate, graduate, and post-graduate students. The students at the public university consisted only of undergraduate students. A total of 376 students responded to the survey. The respondents used QuestionPro survey software to submit their results directly into an electronic database for analysis. Statistical frequencies and statistical tests were conducted in SPSS 21.0 (Statistical Package for the Social Sciences) statistical software in order to address the research questions.

\section{RESULTS}

To answer the first research question: "Does age and/or gender of students affect perceived effectiveness of onground instruction?," regression analysis was performed using SPSS. Specifically, the data were analyzed to determine whether age and/or gender has a significant influence on the perceived effectiveness of on-ground instruction (see results in Tables 1-3). Neither gender nor age has a significant impact on perceived effectiveness of on-ground instruction. Hence, there were no gender or age differences with respect to traditional on-ground education. These results served as a baseline for our subsequent research questions. Since no difference was found in the perceived effectiveness of on-ground instruction based on age or gender, it may be expected that one would find no differences in effectiveness either in online or hybrid instructions. These findings are addressed in the next research questions.

Table 1. Model Summary of Perceived Effectiveness of On-Ground Instruction

\begin{tabular}{|l|l|l|l|l|}
\hline Model & R & R Square & \multicolumn{1}{|c|}{$\begin{array}{c}\text { Adjusted R } \\
\text { Square }\end{array}$} & $\begin{array}{c}\text { Std. Error of the } \\
\text { Estimate }\end{array}$ \\
\hline 1 & $.075^{\mathrm{a}}$ & .006 & -.005 & .94425 \\
\hline
\end{tabular}

a. Predictors: (Constant), age, gender

Table 2. ANOVA Test of Perceived Effectiveness of On-Ground Instruction by Age and Gender

\begin{tabular}{|l|l|l|l|l|l|l|}
\hline Model & & \multicolumn{1}{|c|}{$\begin{array}{c}\text { Sum of } \\
\text { Squares }\end{array}$} & \multicolumn{1}{|c|}{ df } & $\begin{array}{c}\text { Mean } \\
\text { Square }\end{array}$ & \multicolumn{1}{|c|}{ F } & Sig. \\
\hline \multirow{2}{*}{1} & Regression & .931 & 2 & .465 & .522 & $.594^{\mathrm{b}}$ \\
\cline { 2 - 8 } & Residual & 166.732 & 187 & .892 & & \\
\cline { 2 - 7 } & Total & 167.663 & 189 & & & \\
\hline
\end{tabular}


Table 3. Coefficients of Perceived Effectiveness of On-Ground Instruction by Age and Gender

\begin{tabular}{|l|l|l|l|l|l|l|}
\hline Model & & $\begin{array}{c}\text { Unstandardized } \\
\text { Coefficients B }\end{array}$ & $\begin{array}{c}\text { Std. } \\
\text { Error }\end{array}$ & $\begin{array}{c}\text { Standardized } \\
\text { Coefficients Beta }\end{array}$ & t & Sig. \\
\hline \multirow{2}{*}{1} & (Constant) & 1.897 & .241 & & 7.866 & .000 \\
\cline { 2 - 8 } & gender & .131 & .149 & .066 & .883 & .378 \\
\cline { 2 - 8 } & age & -.047 & .069 & -.051 & -.684 & .495 \\
\hline
\end{tabular}

a. Dependent Variable: Perceived effectiveness of on-ground instruction

To answer the second research question: "Does age and/or gender of students affect perceived effectiveness of online instruction?," regression analysis was performed to determine whether age and/or gender has a significant influence on the perceived effectiveness of online instruction (see results in Tables 4-6). Overall, gender does not have a significant impact on level of perceived effectiveness of online instruction. Age does have a significant impact on the perceived effectiveness of online instruction $(\mathrm{p}=0.029)$. Older students regard online education as more effective than younger students. This is a bit counterintuitive, since younger individuals are often described as being more "tech-savvy" and skilled and are often earlier adopters of technology. It is likely that maturity and selfdiscipline increase with age and allow for greater success on the part of older individuals in online learning.

An f-test was performed to see if there were any interaction effects between age and gender, and perceived effectiveness (see results in Tables 7 and 8). For example, do older females have a different perception than younger males? Overall, no interaction effects were found. The findings and conclusions regarding higher perceived effectiveness of online instruction by older students still holds true.

Table 4. Model Summary of the Perceived Effectiveness of Online Instruction by Age and Gender

\begin{tabular}{|l|l|l|l|l|}
\hline Model & \multicolumn{1}{|c|}{$\mathbf{R}$} & R Square & Adjusted R Square & \multicolumn{1}{c|}{$\begin{array}{c}\text { Std. Error of the } \\
\text { Estimate }\end{array}$} \\
1 & $.159^{\mathrm{a}}$ & .025 & .015 & 1.60104 \\
a. Predictors: (Constant), gender, age & & \\
\hline
\end{tabular}

Table 5. ANOVA Test of the Perceived Effectiveness of Online Instruction by Age and Gender

\begin{tabular}{|l|l|l|l|l|l|l|}
\hline Model & & Sum of Squares & df & Mean Square & F & Sig. \\
\hline \multirow{2}{*}{1} & Regression & 12.426 & 2 & 6.213 & 2.424 & .091 \\
\cline { 2 - 7 } & Residual & 479.343 & 187 & 2.563 & & \\
\cline { 2 - 7 } & Total & 491.768 & 189 & & & \\
\hline
\end{tabular}


Table 6. Coefficients of the Perceived Effectiveness of Online Instruction by Age and Gender

\begin{tabular}{|l|l|l|l|l|l|l|}
\hline Model & & $\begin{array}{c}\text { Unstandardized } \\
\text { Coefficients B }\end{array}$ & $\begin{array}{c}\text { Std. } \\
\text { Error }\end{array}$ & $\begin{array}{c}\text { Standardized } \\
\text { Coefficients Beta }\end{array}$ & t & Sig. \\
\hline \multirow{3}{*}{1} & (Constant) & 4.190 & .409 & & 10.246 & .000 \\
\cline { 2 - 8 } & age & -.259 & .117 & -.162 & -2.202 & .029 \\
\cline { 2 - 8 } & gender & .119 & .252 & .035 & .473 & .637 \\
\hline
\end{tabular}

a. Dependent Variable: Perceived effectiveness of online instruction

To answer the third research question: "Does age and/or gender of students affect perceived effectiveness of hybrid instruction?," regression analysis was performed to test whether age and/or gender has a significant influence on the perceived effectiveness of hybrid instruction (see results in Tables 9-11). Overall, both age and gender have significant impacts on the perceived effectiveness of hybrid instruction ( $\mathrm{p}=0.015$ and $\mathrm{p}=0.028$ ). Older students and female students regard hybrid instructions as more effective. The stronger acceptance by older individuals was expected here, due to the results found in research question two; however, the gender difference was unexpected. Perhaps there is a maturity aspect here as well? Further study is recommended to determine the reason for this difference.

Table 7. Between-Subjects Factors Categories and Sample Size

\begin{tabular}{|c|c|c|}
\hline Between-Subject Factors & Category & N \\
\hline Age & 1 & 35 \\
\cline { 2 - 3 } & 2 & 79 \\
\cline { 2 - 3 } & 3 & 43 \\
\cline { 2 - 3 } & 4 & 30 \\
\cline { 2 - 3 } & 5 & 3 \\
\hline \multirow{2}{*}{ Gender } & 1 & 127 \\
\cline { 2 - 3 } & 2 & 63 \\
\hline
\end{tabular}

Table 8. Tests of Between-Subjects Effects of the Perceived Effectiveness of Online Instruction by Age and Gender Examining Interaction Effects

\begin{tabular}{|l|c|c|c|c|c|}
\hline $\begin{array}{l}\text { Dependent Variable: Perceived effectiveness } \\
\text { of Online Instruction }\end{array}$ & $\begin{array}{c}\text { Type III Sum } \\
\text { of Squares }\end{array}$ & df & $\begin{array}{c}\text { Mean } \\
\text { Square }\end{array}$ & F & Sig. \\
\hline Corrected Model & $46.605^{\text {a }}$ & 9 & 5.178 & 2.094 & .032 \\
\hline Intercept & 717.352 & 1 & 717.352 & 290.058 & .000 \\
\hline Age & 22.646 & 4 & 5.661 & 2.289 & .062 \\
\hline Gender & 3.732 & 1 & 3.732 & 1.509 & .221 \\
\hline Age * Gender & 16.786 & 4 & 4.197 & 1.697 & .153 \\
\hline Error & 445.163 & 180 & 2.473 & & \\
\hline Total & 3130.000 & 190 & & & \\
\hline Corrected Total & 491.768 & 189 & & & \\
\hline a. R Squared =.095 (Adjusted R Squared $=.050)$ \\
\hline
\end{tabular}


Table 9. Model Summary of Perceived Effectiveness of Hybrid Instruction by Age and Gender

\begin{tabular}{|l|l|l|l|l|} 
Model & \multicolumn{1}{|c|}{$\mathbf{R}$} & $\begin{array}{c}\mathbf{R} \\
\text { Square }\end{array}$ & \multicolumn{1}{|c|}{$\begin{array}{c}\text { Adjusted R } \\
\text { Square }\end{array}$} & $\begin{array}{c}\text { Std. Error of the } \\
\text { Estimate }\end{array}$ \\
\hline 1 & $.261^{\mathrm{a}}$ & .068 & .058 & 1.04563 \\
\hline \multicolumn{3}{|l}{ a. Predictors: (Constant), gender, age } \\
\hline
\end{tabular}

Table 10. ANOVA Test of the Perceived Effectiveness of Hybrid Instruction by Age and Gender

\begin{tabular}{|l|l|l|l|l|l|l|}
\hline Model & & \multicolumn{1}{|c|}{$\begin{array}{c}\text { Sum of } \\
\text { Squares }\end{array}$} & \multicolumn{1}{|c|}{ df } & \multicolumn{1}{|c|}{$\begin{array}{c}\text { Mean } \\
\text { Square }\end{array}$} & F & Sig. \\
\hline \multirow{2}{*}{1} & Regression & 14.962 & 2 & 7.481 & 6.843 & $.001^{\mathrm{b}}$ \\
\cline { 2 - 7 } & Residual & 204.453 & 187 & 1.093 & & \\
\cline { 2 - 7 } & Total & 219.416 & 189 & & & \\
\hline \\
a. Dependent Variable: Perceived effectiveness of hybrid instruction \\
\hline
\end{tabular}

Table 11. Coefficients of the Perceived Effectiveness of Hybrid Instruction by Age and Gender

\begin{tabular}{|l|l|l|l|l|l|l|}
\hline Model & & $\begin{array}{c}\text { Unstandardized } \\
\text { Coefficients B }\end{array}$ & Std. Error & \multicolumn{1}{|c|}{$\begin{array}{c}\text { Standardized } \\
\text { Coefficients Beta }\end{array}$} & t & Sig. \\
\hline \multirow{3}{*}{1} & (Constant) & 3.458 & .267 & & 12.950 & .000 \\
\cline { 2 - 7 } & age & -.188 & .077 & -.176 & -2.447 & .015 \\
\cline { 2 - 7 } & gender & -.365 & .165 & -.160 & -2.216 & .028 \\
\hline
\end{tabular}

To answer the fourth research question: "Does age and/or gender affect choice of online instruction method?," regression analysis was performed to test whether age and/or gender has a significant influence on the choice of online instruction method (see results in Tables 12-15). Overall, neither gender nor age has an impact on whether online instruction was chosen, versus other methods of delivery. This finding represents an interesting dichotomy with regard to online education. There is no difference in choosing online instructions between younger and older students; however, as noted in the results of research question two, older students perceive more effectiveness in online instructions than younger students. If given a choice, generally most students, neither older nor younger students would choose online instructions. If there is no choice of choosing between online instructions vs. onground or hybrid instructions, that is, students have no choice but to take online courses, then older students perceive more effectiveness of online instructions than younger students. Some of the age issue may also be explained by the significant interaction effect $(p=.046)$ between age and gender on the choice of online education (see result in Table 15). Males over all age groups are fairly constant in their choice of preferring on-ground instruction. Younger females show a higher acceptance of online education than males but older females show a much higher preference for on-ground courses. 
Table 12. Model Summary of Choice of Online Instruction by Age and Gender

\begin{tabular}{|l|l|l|l|l|} 
Model & \multicolumn{1}{|c|}{$\mathbf{R}$} & R Square & $\begin{array}{c}\text { Adjusted R } \\
\text { Square }\end{array}$ & $\begin{array}{c}\text { Std. Error of the } \\
\text { Estimate }\end{array}$ \\
\hline 1 & .150 & .022 & .014 & 0.48376 \\
\hline
\end{tabular}

a. Predictors: (Constant), gender, age

Table 13. ANOVA Test of Choice of Online Instruction by Age and Gender

\begin{tabular}{|l|l|l|l|l|l|l|}
\hline Model & & \multicolumn{1}{|c|}{$\begin{array}{c}\text { Sum of } \\
\text { Squares }\end{array}$} & df & \multicolumn{1}{|c|}{$\begin{array}{c}\text { Mean } \\
\text { Square }\end{array}$} & F & Sig. \\
\hline \multirow{3}{*}{1} & Regression & 1.301 & 2 & 0.650 & 2.779 & .064 \\
\cline { 2 - 7 } & Residual & 56.634 & 242 & 0.234 & & \\
\cline { 2 - 7 } & Total & 57.935 & 244 & & & \\
\hline
\end{tabular}

Table 14. Coefficients of Choice of Online Instruction by Age and Gender

\begin{tabular}{|l|l|l|l|l|l|l|}
\hline \multirow{2}{*}{ Model } & & $\begin{array}{c}\text { Unstandardized } \\
\text { Coefficients B }\end{array}$ & $\begin{array}{c}\text { Std. } \\
\text { Error }\end{array}$ & $\begin{array}{c}\text { Standardized } \\
\text { Coefficients Beta }\end{array}$ & t & Sig. \\
\hline \multirow{2}{*}{1} & (Constant) & 1.848 & .109 & & 16.907 & .000 \\
\cline { 2 - 7 } & age & -.059 & .031 & -.123 & -1.908 & .058 \\
\cline { 2 - 7 } & gender & -.067 & .066 & -.066 & -1.018 & .310 \\
\hline
\end{tabular}

Table 15. Tests of Between-Subjects Effects of the Choice of Online Instruction by Age and Gender Examining Interaction Effects

\begin{tabular}{|l|l|l|l|l|l|}
\hline \multicolumn{1}{|c|}{$\begin{array}{c}\text { Dependent Variable: Choice of online } \\
\text { instruction }\end{array}$} & $\begin{array}{c}\text { Type III Sum } \\
\text { of Squares }\end{array}$ & \multicolumn{1}{|c|}{ df } & \multicolumn{1}{c|}{$\begin{array}{c}\text { Mean } \\
\text { Square }\end{array}$} & F & Sig. \\
\hline Corrected Model & 4.555 & 9 & 506 & 2.228 & .021 \\
\hline Intercept & 11.128 & 1 & 11.128 & 49.989 & .000 \\
\hline Age & 2.007 & 4 & 0.502 & 2.209 & .069 \\
\hline Gender & 0.593 & 1 & 0.593 & 2.610 & .108 \\
\hline age gender & 2.232 & 4 & 0.558 & 2.457 & .046 \\
\hline Error & 53.379 & 235 & 0.227 & & \\
\hline Total & 94.000 & 245 & & & \\
\hline Corrected Total & 57.935 & 244 & & & \\
\hline a. R Squared $=.079$ (Adjusted R Squared $=.043)$ & & & & \\
\hline
\end{tabular}




\section{CONCLUSIONS}

This study concludes that age and gender have various impact on the different formats of education. First, age and gender have no impact on the perceived effectiveness of on-ground education. This is somewhat surprising given that many researchers have found differences in perceptions and use of technology by age and gender. The fact that no differences in perceived effectiveness were found indicates that colleges do not have to modify their on-ground programs based on gender or age.

Second, age, but not gender, has an impact on the perceived effectiveness of online education. Older students perceive more effectiveness than younger students. This suggests that more work may need to be done to influence younger students on online usage and materials. This difference may be due to lack of maturity and self-motivation on the part of younger students.

Third, both age and gender have impacts on the perceived effectiveness of hybrid education. Older students and female students perceive more effectiveness in hybrid education. As a result, hybrid education delivery may need to be customized based on gender and age.

Finally, neither age nor gender affects the choice of online versus on-ground or hybrid education though there is an interaction effect with both age and gender. Younger females show a higher acceptance of online education than younger males. This again may be a maturity effect or there may be some inherent difference in learning methods between younger males and females. Further study is needed to address the subtly differences in different formats of education and what factors lead or do not lead to the different perceptions and/or choices from students in different age and gender groups. 


\section{REFERENCES}

Balakrishnan, V., \& Yeow, P. (2007). Texting satisfaction: does age and gender make a difference? International Journal of Computer Science and Security, 1(1), 85-96.

Fallows, D. (2005). How women and men use the Internet. Retrieved from http://www.pewinternet.org/Reports/2005/How-Women-and-Men-Use-the-Internet

Herring, S. C., \& Zelenkauskaite, A. (2009). Symbolic capital in a virtual heterosexual market abbreviation and insertion in Italian SMS. Written Communication, 26(1), 5-31.

Igarashi, T., Jiro, T., \& Toshikazu, Y. (2005). Gender differences in social network development via mobile phone messages: a longitudinal study. Journal of Social and Personal Relationships, 22(5), 591-713.

Kimbrough, A. M., Guadagnob, R. E., Muscanelle, N., \& Dilld, J. (2013). Gender differences in mediated communication: Women connect more than do men. Computers in Human Behavior, 29(3), 896-900.

Moghaddam, G. G. (2010) Information technology and gender gap: Toward a global view. The Electronic Library, 28(5), $722-733$.

Peslak, A., Ceccucci, W., Kruck, S. \& Sendall, P. (2013). Does gender play a role in text messaging? Issues in Information Systems, 14(2), 186-194.

Portio Research (2012). Mobile messaging futures 2012-2016. Retrieved from https://karlwhitfield.files.wordpress.com/2012/12/mobile-messaging-futures-2012-2016-portio-researchltd-full-report.pdf

Pruthikrai, M. (2007). The effects of personality traits and optimum stimulation level on text-messaging activities and m-commerce Intention. International Journal of Electronic Commerce, 12(1), 7-30.

Snell, S., \& Snell-Siddle, C. (2013). Mobile learning: the effects of gender and age on perceptions of the use of mobile tools. The Second International Conference on Informatics Engineering \& Information Science (ICIEIS), Universiti Teknologi Malaysia (UTM), Kuala Lumpur, Malaysia.

Venkatesh, V., \& Morris, M. (2000). Why don't men ever stop to ask for directions? Gender, social influence, and their role in technology acceptance and usage behavior. MIS Quarterly, 24(1), 115-139.

Venkatesh, V., Thong, J., \& Xu, X. (2012). Consumer acceptance and use of information technology: extending the unified theory of acceptance and use of technology. MIS Quarterly, 36(1), 157-178.

Yau, H. K., \& Cheng, A. L. F. (2012). Gender difference of confidence in using technology for learning. Journal of Technology Studies, 38(2), 74-79. 